\title{
Dynamic Connectedness and Portfolio Diversification during the Coronavirus Disease 2019 Pandemic: Evidence from the Cryptocurrency Market ${ }^{*}$
}

\author{
Samia Nasreen \\ Lahore College for Women University, Lahore, Pakistan \\ E-mail:sami_lcu@yahoo.com \\ Aviral Kumar Tiwari \\ Rajagiri Business School, Rajagiri Valley Campus, Kochi, India \\ E-mail: aviral.eco@gmail.com \\ Seong-Min Yoon $^{\dagger}$ \\ Department of Economics, Pusan National University, Busan, Republic of Korea. \\ E-mail:smyoon@pusan.ac.kr
}

\footnotetext{
* This work was supported by the Ministry of Education of the Republic of Korea and the National Research Foundation of Korea (NRF-2020S1A5B8103268).

$\uparrow$ Corresponding author. Department of Economics, Pusan National University, 2, Busandaehak-ro 63beongil, Geumjeong-gu, Busan, 46241, Korea. Tel: +82-51-510-2557. Fax: +82-51-581-3143. E-mail: smyoon@pusan.ac.kr
} 


\title{
Dynamic Connectedness and Portfolio Diversification during the Coronavirus Disease 2019 Pandemic: Evidence from the Cryptocurrency Market
}

\begin{abstract}
This paper examines interlinkages and hedging opportunities between nine major cryptocurrencies for the period between 30 September 2015 and 4 June 2020, which notably includes the coronavirus disease 2019 (COVID-19) outbreak lasting from early 2020 through the end of the sample period. The results of dynamic conditional correlation (DCC) analysis using a minimum connectedness approach show a high degree of correlation between cryptocurrencies throughout the sample period. However, the correlations reach their minimum values during the COVID-19 pandemic, which indicates that cryptocurrencies acted as a hedge or safe haven during the stressful period of the COVID-19 pandemic. The weight of cryptocurrencies was significantly reduced and their hedging effectiveness varied greatly during the pandemic, which indicates that investors' preferences changed during the COVID-19 period.
\end{abstract}

Keywords: Cryptocurrency; Coronavirus Disease 2019; Time-Varying Parameter Vector Autoregression; Portfolio Weight; Hedging Effectiveness

JEL classification: F21, F65, G11, G15

\footnotetext{
*Abbreviations: USD, US dollars; DCC, dynamic conditional correlation; TVP-VAR, time-varying parameter vector autoregression; COVID-19, coronavirus disease 2019; HE, hedge effectiveness index
} 


\section{Introduction}

In recent years, cryptocurrency has emerged as a new asset class and become an integral part of global financial markets (Ji et al., 2019). Exponential growth has been observed in both its market capitalisation and the number of digital coins available. Its market capitalisation increased from around 128.8 billion US dollars (USD) in 2018 to 237.1 billion USD in 2019. At the start of 2015, the market capitalisation shares of Bitcoin, the first cryptocurrency, was over $85 \%$ of the cryptocurrency market. Since the introduction of new cryptocurrencies such as Ethereum, Ripple, Steller, Dash and Litecoin, Bitcoin's market capitalisation share started gradually decreasing, suggesting investors' preference for alternative cryptocurrencies. Today, there are over 1,000 cryptocurrencies that have attracted substantial interest from many scholars in both theoretical and empirical fields. As a consequence, a number of studies has emerged that analyse the main characteristics of these newly created currencies, including their market efficiency (Brauneis and Mestel, 2018; Aggarwal, 2019; Bundi and Wildi, 2019; Chaim and Laurini, 2019; Zargar and Kumar, 2019; Tran and Leirvik, 2020); risk and returns (Caporale and Zekokh, 2019; Ji et al., 2019; Katsiampa et al., 2019; Palamalai and Maity 2019; Moratis, 2020) and diversification or hedging properties (Bouri et al., 2017a, 2017b; Corbet et al., 2018; Guesmi et al., 2019; Stensås et al., 2019; Demir et al., 2020). The outbreak of the coronavirus disease 2019 (COVID-19) pandemic created a strong contagion effect across global financial markets, leading to an immediate economic downturn and unprecedented levels of economic uncertainty. It currently poses exceptional health, economic and financial stability challenges worldwide. Financial markets have witnessed a sharp decline in the prices of financial assets, a deterioration in market liquidity and volatility spikes (Gopinath, 2020). Consequently, academic literature 
examining the responses of various financial assets and markets to the pandemic is rapidly emerging (see, e.g. Akhtaruzzaman et al., 2020; Corbet et al., 2020; Demir et al., 2020; Goodell and Goutte, 2021; Liu et al., 2020; Sharif et al., 2020; Yarovaya et al., 2020; and Zhang et al., 2020).

The impact of COVID-19 is an unprecedented shock to the relatively new cryptocurrency market. Thus, cryptocurrency as a financial asset has not yet been proven to exhibit safe haven properties during periods of stress or crisis. Initial evidence suggests that cryptocurrencies have failed to present safe haven properties and hedging opportunities during the stressful COVID-19 pandemic period (Conlon and McGee, 2020; Corbet et al., 2020). Given these findings, the effect of COVID-19 on cryptocurrency can be considered to have had a so-called 'black swan effect', triggering behavioural anomalies such as conditional and unconditional herding.

Knowledge about cryptocurrencies and understanding of their interlinkages is imperative for risk management, portfolio diversification and hedging opportunities. Investors are interested in learning the degree of contagion risk when trading cryptocurrencies and choosing the best cryptocurrency to diversify their portfolio according to their risk preferences (Kouttmos, 2018). The major focus of long-term investors is on long-run market connectedness, for speculators concern it is short-run market volatility and for hedgers it is the highest degree of correlation in the medium to long term. With these goals in mind, this paper contributes to the literature on financial contagion by examining the impact of the COVID-19 pandemic on the interrelationship between the major cryptocurrencies and its implications for portfolio design.

This paper contributes to the existing literature in several ways. First, to the best of our knowledge, this is the first attempt to investigate the diversification/hedging 
properties of cryptocurrencies during the COVID-19 pandemic. Second, this paper estimates both full sample results as well as results for the pandemic time period only to enrich the analysis and identify changes in investor behaviour attributable to the pandemic. Thirdly, the current connectedness literature is refined and extended by employing a time-varying parameter vector autoregression (TVP-VAR) approach, which has advantages over Diebold and Yilmaz's (2012) connectedness methodology in terms of size and power. Finally, this paper constructed both univariate and bivariate dynamic portfolios by employing a minimum connectedness portfolio and a bivariate dynamic portfolio.

Empirical evidence from dynamic conditional correlation (DCC) analysis demonstrates a high value of correlation between cryptocurrencies in early 2018 due to market uncertainty. Cryptocurrencies became more volatile during the COVID-19 period and functioned like a safe haven during the pandemic. The weight of cryptocurrencies was also significantly reduced during the pandemic, which indicates a change in investor preferences during the COVID-19 period.

The remainder of this paper is organised as follows. Section 2 describes the econometric methods, data and statistical characteristics. Section 3 presents and discusses the empirical results and Section 4 concludes.

\section{Materials and Methods}

\subsection{Data}

We use daily data from nine cryptocurrencies — namely, Bitcoin (BTC), Ethereum (ETH), Stellar (XLM), Nem/New Economy Movement (XEM); Ripple (XRP), Litecoin (LTC), Dash (DASH), Monero (XMR) and Bitshares (BTS) - for the period between 30 
September 2015 and 4 June 2020, ${ }^{*}$ which includes the COVID-19 pandemic period that lasted from early 2020 until the end of the study period. The main reason for selecting this period was to ensure the availability of a balanced dataset without any missing observations. On 6 June 2020, the cryptocurrency market's total capitalisation was 276.1 billion USD and these nine cryptocurrencies' share in total market capitalisation was $81.38 \%$. We use cryptocurrency returns for empirical analysis because their prices exhibit non-stationary behaviour (Antonakakis et al., 2019). The summary statistics of returns presented in Table 1 show that the average value of returns per day varied between 0.075 (BTS) and 0.341 (ETH) and that all coins, except for ETH and BTC, exhibited a leftskewed tail. Interestingly, both the lowest and highest values in returns can be observed for XRP. In addition, the returns of selected cryptocurrencies follow a leptokurtic distribution.

$$
<<\text { Insert Table } 1 \text { about here }>>
$$

\subsection{Econometric Methods}

In this paper, we explore the DCCs and time-varying measures of portfolio diversification using a minimum connectedness approach. The dynamic connectedness method was originally proposed by Diebold and Yilmaz $(2012,2014)$ and is widely used by practitioners and researchers because it provides both static and dynamic methods for time-series connectedness analysis. Under this approach, the vector autoregression (VAR) model (Sims, 1980) is employed for static analysis while the rolling-window VAR approach is used for dynamic analysis. Antonakakis et al. (2019) intensively discussed the setting of this framework and proposed the TVP-VAR

\footnotetext{
* All sample data sets have been downloaded from Thompson Reuters Eikon. Restrictions apply to the availability of these data, which were used under license for this study. Data are available at https://eikon.thomsonreuters.com with the permission of Thomson Reuters Eikon.
} 
methodology using a dynamic connectedness approach to avoid the dynamics being affected by the size of the rolling window. Additional advantages of this approach are as follows: (i) time-varying variance of the VAR coefficients and their error terms; (ii) there is no need to randomly select the rolling-window size; (iii) there is no loss of information and (iv) it can be employed for a low-frequency dataset. We are employing a TVP-VAR model based on the Bayesian information criterion, which can be written as:

$$
\begin{aligned}
& k_{t}=\theta_{t} k_{t-1}+v_{t} \quad v_{t} \sim N\left(0, R_{t}\right), \\
& \operatorname{vec}\left(\theta_{t}\right)=\operatorname{vec}\left(\theta_{t-1}\right)+\varpi_{t} \quad \varpi_{t} \sim N\left(0, P_{t}\right) .
\end{aligned}
$$

where $k_{t}, k_{t-1}$ and $v_{t}$ are $m \times 1$ dimensional vectors, $\theta_{t}$ and $R_{t}$ are $m \times m$ dimensional matrices, $\operatorname{vec}\left(\theta_{t}\right)$ and $\varpi_{t}$ are $m^{2} \times 1$ dimensional vectors, and $P_{t}$ is an $m^{2} \times m^{2}$ dimensional matrix.

According to world representation theorem, TVP-VAR model is transformed to time-varying parameter-vector moving average (TVP-VMA) by using following equality: $k_{t}=\sum_{j=1}^{n} \theta_{j t} k_{t-j}+v_{t}=\sum_{i=0}^{\infty} B_{i t} v_{t-i}$. The time-varying coefficients $\left(B_{i t}\right)$ of the TVP-VMA model are the cornerstone of Diebold and Yilmaz's (2014) connectedness approach that have used generalized impulse response functions (GIRF), $\vartheta_{i j, t}^{l}$ and $H$ step-ahead generalized forecast error variance decomposition (GFEVD), $\tilde{\pi}_{i j, t}^{l}(H)$ proposed by Koop et al. (1996) and Pesaran and Shin (1998). Hence, GFEVD represents the influence of variable $i$ on variable $j$ in terms of its forecast error variance share and can be computed as:

$$
\tilde{\pi}_{i j, t}^{l}(H)=\frac{\sum_{t=1}^{H-1} \vartheta_{i j, t}^{2, l}}{\sum_{j=1}^{n} \sum_{t=1}^{H-1} \vartheta_{i j, t}^{2, l}} .
$$

With $\sum_{j=1}^{n} \tilde{\pi}_{i j, t}^{l}(H)=1$ and $\sum_{i j=1}^{n} \tilde{\pi}_{i j, t}^{l}(H)=n$. Based on GFEVD, total connectedness index represents the interdependence of variables and is formulated as: 


$$
C_{t}^{l}(H)=\frac{\sum_{i j=1, i \neq j}^{n} \widetilde{\pi}_{i j, t}^{l}(H)}{\sum_{i j=1}^{n} \widetilde{\pi}_{i j, t}^{l}(H)} * 100
$$

Total directional connectedness of variable $i$ To (FROM) other variables $j$ is defined as

$$
C_{i \rightarrow j, t}^{l}(H)=\frac{\sum_{j=1, i \neq j}^{n} \widetilde{\pi}_{j i, t}^{l}(H)}{\sum_{j=1}^{n} \widetilde{\pi}_{j i, t}^{l}(H)} * 100, \quad \text { or } \quad C_{i \leftarrow j, t}^{l}(H)=\frac{\sum_{j=1, i \neq j}^{n} \widetilde{\pi}_{i j, t}^{l}(H)}{\sum_{j=1}^{n} \widetilde{\pi}_{i j, t}^{l}(H)} * 100
$$

Net total directional connectedness which is the difference between total directional connectedness To others and From others is defined as

$$
C_{i, t}^{l}=C_{i \rightarrow j, t}^{l}(H)-C_{i \leftarrow j, t}^{l}(H),
$$

Finally, net pairwise directional connectedness is given as:

$$
C_{i j}(J)=\left(\frac{\tilde{\pi}_{j i, t}(J)-\widetilde{\pi}_{i j, t}(J)}{N}\right) * 100
$$

Net total directional connectedness examines the influence of variable $i$ on variable $j$ or vice versa.

An optimal portfolio weight that minimises risk without lowering expected returns is constructed using Kroner and Ng's (1998) approach. The optimal portfolio weight, $w_{i j, t}$, between cryptocurrency $i$ and $j$ is constructed using conditional covariance $\left(h_{i j}\right)$ as follows:

$$
w_{i j, t}=\frac{h_{j j, t}-h_{i j, t}}{h_{i i, t}-2 h_{i j, t}+h_{j j, t}}
$$

where $w_{i j, t}$ can be greater than one or less than zero. The following restrictions are imposed to overcome this disadvantage:

$$
w_{i j, t}= \begin{cases}0 & \text { if } w_{i j, t}<0 \\ w_{i j, t} & \text { if } 0 \leq w_{i j, t} \leq 1 \\ 1 & \text { if } w_{i j, t}>1\end{cases}
$$

where $w_{i j, t}$ is the weight of asset $i$ in a 1-USD portfolio based on two assets, $i$ and $j$, at time $t$. The second weight regarding asset $j$ is $w_{j i, t}=\left(1-w_{i j, t}\right)$. 
Following Kroner and Sultan (1993), to minimise risk, the optimal hedge ratio of two cryptocurrencies $m$ and $n$ is computed as follows:

$$
\beta_{i j, t}=\frac{h_{i j, t}}{h_{j j . t}}
$$

where $\beta$ is a hedge ratio with a 1-USD long position in cryptocurrency $i$ and a 1-USD short position in cryptocurrency $j . h_{i j, t}$ is the conditional covariance between the returns on cryptocurrencies $i$ and $j$ and $h_{j j . t}$ is the conditional variance of cryptocurrency $j$.

The hedge effectiveness index (HE) proposed by Ederington (1979) is used to evaluate the performance of a hedged portfolio. $H E$ is a comparison of risk between a hedged and an unhedged portfolio and can be written as:

$$
\begin{aligned}
& \eta_{\beta}=y_{i, t}-\beta_{i j, t} y_{j, t}, \\
& \eta_{w}=w_{i j, t} y_{i, t}+\left(1-w_{i j, t}\right) y_{j, t}, \\
& H E_{i}=1-\frac{v\left(\eta_{w, \beta}\right)}{v\left(\eta_{\text {unhedged }}\right)},
\end{aligned}
$$

where $v\left(\eta_{\text {unhedged }}\right)$ indicates the variance of the unhedged position of asset $i$ and $v\left(\eta_{w, \beta}\right)$ is the variance of a hedged portfolio either from the optimal dynamic hedge ratio or the optimal dynamic portfolio weight strategy. A higher $H E_{i}$ illustrates a larger reduction in the risk of the portfolio.

\section{Discussion}

Given that the aim of this study is to examine the connectedness and hedging benefits of cryptocurrencies and investigate financial contagion due to the COVID-19 outbreak, it is imperative to examine the DCC based on the TVP-VAR method between the selected cryptocurrencies. The results for the full sample period, as well as for the 
COVID-19 pandemic period only, are presented in Figure 1. From Figure 1 (a), the DCC results clearly demonstrate the high value of correlations between cryptocurrencies in early 2018. The reason for this more pronounced connectedness between cryptocurrencies is market uncertainty that arose in early 2018 in response to the sharp collapse of Bitcoin. These findings are in line with Antonakakis et al. (2019), who posited that market uncertainty was the main factor for increasing interdependence between cryptocurrencies. From Figure 1 (b), some interesting facts can be observed. (1) Connectedness between cryptocurrencies is positive from February to March 2020 and reaches its highest value in mid-February 2020. (2) From March to June 2020, the connectedness between most cryptocurrencies was negative. (3) Connectedness reached its minimum value in mid-March 2020. In other words, there initially was positive interdependence between cryptocurrencies but with the increase in the number of reported COVID-19 cases and deaths, the interdependence became negative. This evidence implies that at the beginning, cryptocurrencies functioned like a traditional asset, but after the increase in the negative effects of COVID-19, they began acting like a hedge. This evidence is similar to the findings of Demir et al. (2020, 2018), who argued that cryptocurrencies act like a hedge during periods of uncertainty but contradicts the findings of Conlon and McGee (2020) and Corbet et al. (2020), who asserted that cryptocurrencies do not act as hedges or safe havens during periods of economic and financial turmoil but rather function as amplifiers of contagion.

$$
<<\text { Insert Figure } 1 \text { about here }>>
$$

Next, we estimate the optimal weight created by the minimum connectedness portfolio, which is based on TVP-VAR using the Diebold and Yilmaz (DY) method. The results are shown in Table 2 . The weight assigned to cryptocurrencies shows considerable 
volatility over the sample period. For example, the highest average weight is observed for BTS $(17 \%)$ and the lowest average weight for Ethereum $(6 \%)$. The highest value of hedging effectiveness is observed for Nem/New Economy Movement (73\%), followed by Steller (72\%) and BTS (69\%). Similarly, during the COVID-19 period, the highest average weight and HE values of $29 \%$ and $69 \%$, respectively, are observed for BTS.

$$
<<\text { Insert Table } 2 \text { about here }>>
$$

For additional clarity, we computed the bilateral portfolio weights and hedge ratios in the spirit of Kroner and $\mathrm{Ng}$ (1998) and Kroner and Sultan (1993). The results are displayed in Tables 3 and 4. From Table 3, for the full sample period, the lowest average weight $(0.12)$ is observed for the XMR/BTC portfolio, indicating that investors preferred to hold BTC more than XMR. The highest average weight $(0.88)$ is noted for BTC/XMR, demonstrating that, for a 1-USD portfolio, investors preferred to invest 0.88 cents in BTC and the remaining 0.12 cents in XMR. The highest HE of $72 \%$ is obtained for a portfolio composed of XLM/BTC, indicating that the introduction of BTC into a portfolio of cryptocurrencies significantly improves its risk return characteristics. Furthermore, the optimal weights are found to be time-varying throughout the sample period, implying that active portfolio management is required when investing in the cryptocurrency market. However, during the COVID-19 period, the cryptocurrencies become more volatile, as can be seen in the average optimal portfolio weights between pairs of cryptocurrencies, which vary between $0.03(\mathrm{ETH} / \mathrm{XRP})$ and $0.97(\mathrm{XRP} / \mathrm{ETH})$, indicating that XRP has the highest optimal portfolio weight during the COVID-19 period. Thus, increased volatility within the bivariate portfolio weight during the COVID-19 period supports the argument that interconnectedness between cryptocurrencies facilitates portfolio and risk management techniques (Antonakakis et al., 2019). 
$<<$ Insert Table 3 about here $>>$

The optimal hedge ratios for both the full sample period and the COVID-19 period are presented in Table 4, demonstrating some interesting insights for portfolio design as most of the optimal hedge ratios changed significantly during the COVID-19 period. Some increased while others decreased. For example, the average hedge ratio for ETH/XLM increased from 0.45 for the full sample period to 1.05 during the COVID-19 period. Similarly, the average hedge ratio for BTS/XLM decreased from 0.22 for the full sample period to -0.02 in the COVID-19 period. A negative hedge ratio occurs when investors take either a long or short position in both cryptocurrencies (Bonga-Bonga and Umoetok, 2016). Likewise, the volatility of HE increased during the COVID-19 period, supporting our previous results estimated by applying a minimum connectedness portfolio. This evidence is consistent with empirical studies that show higher hedge ratios during distress periods (Antonakakis et al., 2018; Batten et al., 2021; Akhtaruzzaman et al., 2020).

$<<$ Insert Table 4 about here $>>$

\section{Conclusion}

Investment in cryptocurrencies was considered to be a safe haven before the outbreak of the COVID-19 pandemic because previous empirical research on the adequacy of cryptocurrency lacked a significant period of financial turmoil in the global equities market to form an informed conclusion regarding its hedging qualities. This paper examined the interlinkages and hedging opportunities between nine cryptocurrencies-Bitcoin, Ethereum, Stellar, Nem/New Economy Movement, Ripple, 
Litecoin, Dash, Monero and BTS—-between 30 September 2015 and 04 June 2020. The study period notably includes the COVID-19 outbreak period, which lasted from early 2020 until the end of the sample period. Thus, our paper sheds new light on the safe haven and diversification properties of cryptocurrencies for global investors.

The findings show significant correlation between cryptocurrencies throughout the sample period and that cryptocurrencies do, in fact, function as hedges or safe havens during the stressful period of the COVID-19 pandemic. In addition, the weight of cryptocurrencies was significantly reduced, and their hedging effectiveness varied greatly during the pandemic, which indicates a change in investor preferences during the COVID19 period. Finally, there is plenty of room for future research on the behaviour of cryptocurrencies, especially during stress periods, because this is a promising field of study with ample applications that might influence contemporary financial markets.

\section{Acknowledgements}

(Removed)

\section{Funding Sources}

(Removed)

\section{References}

Aggarwal, M.D., 2019. Do bitcoins follow a random walk model? Research in Economics, 73, 15-22.

Akhtaruzzaman, M., Boubaker, S., Lucey, B.M., Sensoy, A., 2020. Is gold a hedge or safe haven asset during COVID-19 crisis? https://dx.doi.org/10.2139/ssrn.3621358. 
Antonakakis, N., Chatziantoniou, I., Gabauer, D., 2019. Cryptocurrency market contagion: market uncertainty, market complexity, and dynamic portfolios. Journal of International Financial Markets, Institutions and Money, 61, 37-51.

Batten, J.A., Kinateder, H., Szilagyi, P.G., Wagne, N.F. 2021. Hedging stock with oil. Energy Economics. 93, 104422.

Bonga-Bonga, L., Umoetok, E. 2016. The effectiveness of index futures hedging in emerging markets during the crisis period of 2008-2010: Evidence from South Africa. Applied Economics, 48(42), 3999-4018

Bouri, E., Jalkh, N., Molnár, P., Roubaud, D., 2017a. Bitcoin for energy commodities before and after the December 2013 crash: diversifier, hedge or safe haven? Applied Economics, 49(50), 5063-5073.

Bouri, E., Molnár, P., Azzi,G., Roubaud, D., Hagfors, L.I., 2017b. On the hedge and safe haven properties of bitcoin: is it really more than a diversifier? Finance Research Letters. 20, 192-198.

Brauneis, A., Mestel, R., 2018. Price discovery of cryptocurrencies: bitcoin and beyond. Economics Letters, 165, 58-61.

Bundi, N., Wildi, M., 2019. Bitcoin and market-(in)efficiency: a systematic time series approach. Digital Finance, 1, 47-65.

Caporale, G.M., Zekokh, T., 2019. Modelling volatility of cryptocurrencies using Markov-switching GARCH models. Research in International Business and Finance, 48, 143-155.

Chaim, P., Laurini, M., 2019. Is bitcoin a bubble? Physica A, 517, 222-232.

Conlon, T., Mcgee, R. 2020. Safe haven or risky hazard? Bitcoin during the Covid-19 bear market. Finance Research Letters, 35, 101607.

Corbet, S., Meegan, A., Larkin, C., Lucey, B., Yarovaya, L., 2018. Exploring the dynamic relationships between cryptocurrencies and other financial assets. Economics Letters, 165, 28-34.

Corbet, S., Larkin, C., Lucey, B., 2020. The contagion effects of the COVID-19 pandemic: evidence from gold and cryptocurrencies. Finance Research Letters, $35,101554$. 
Demir, E., Bilgin, M.H., Karabulut, G., Doker, A.C., 2020. The relationship between cryptocurrencies and Covid-19 pandemic. Eurasian Economic Review, 10(3), 349-360.

Diebold, F.X., Yilmaz, K., 2012. Better to give than to receive: predictive directional measurement of volatility spillovers. International Journal of Forecasting, 28(1), 5766.

Diebold, F.X., Y1lmaz, K., 2014. On the network topology of variance decompositions: measuring the connectedness of financial firms. Journal of Econometrics, 182(1), $119-134$.

Ederington, L.H., 1979. The hedging performance of the new futures markets. Journal of Finance. 34(1), 157-170.

Goodell, J.W., Goutte, S., 2021. Co-movement of Covid-19 and bitcoin: evidence from wavelet coherence analysis. Finance Research Letters, 38, 101625.

Gopinath, G., 2020. The great lockdown: worst economic downturn since the great depression. IMF Blog, 14 April.

Guesmi, K., Saadi, S., Abid, I., Ftiti, Z., 2019. Portfolio diversification with virtual currency: evidence from bitcoin. International Review of Financial Analysis, 63, 431-437.

Ji, Q., Bouri, E., Keung, C., Lau, M, Rauboud, D., 2019. Dynamic connectedness and integration in cryptocurrency markets. International Review of Financial Analysis, 63, 257-272.

Katsiampa, P., Corbet, S., Lucey, B., 2019. Volatility spillover effects in leading cryptocurrencies: a BEKK-MGARCH analysis. Finance Research Letters, 29, 6874.

Kouttmos, D., 2018. Return and volatility spillovers among cryptocurrencies. Economics Letters, 173, 122-127.

Kroner, K.F., Ng, V.K., 1998. Modeling asymmetric comovement of asset returns. Review of Financial Studies, 11(4), 817-844. 
Kroner, K.F., Sultan, J., 1993. Time-varying distributions and dynamic hedging with foreign currency futures. Journal of Financial and Quantitative Analysis, 28(4), $535-551$.

Liu, H.Y., Manzoor, A., Wang, C.Y., Zhang, L., Manzoor, Z., 2020. The Covid-19 outbreak and affected countries stock markets response. International Journal of Environmental Research and Public Health, 17(8), 2800.

Moratis, G., 2020. Quantifying the spillover effect in the cryptocurrency market. Finance Research Letters, 38, 101534.

Palamalai, S., Maity, B., 2019. Return and volatility spillover effects in leading cryptocurrencies, Global Economy Journal, 19(3), 1950017.

Sharif A., Aloui C., Yarovaya L., 2020. Covid-19 Pandemic, oil prices, stock market, geopolitical risk and policy uncertainty nexus in the US economy: fresh evidence from the wavelet-based approach. International Review of Financial Analysis, 70, 101496.

Stensås, A., Nygaard, M.F., Kyaw, K., Treepongkaruna, S., 2019. Can bitcoin be a diversifier, hedge or safe haven tool? Cogent Economics \& Finance, 7(1), 1593072.

Tran V., Leirvik T., 2020. Efficiency in the markets of crypto-currencies. Finance Research Letters, 35, 101382.

Yarovaya, L., Brzeszczynski, J., Goodell, J.W., Lucey, B.M., Lau, C.K., 2020. Rethinking financial contagion: information transmission mechanism during the Covid-19 pandemic. http://dx.doi.org/10.2139/ssrn.3602973.

Zargar, F. N., Kumar, D., 2019. Informational inefficiency of bitcoin: a study based on high-frequency data. Research in International Business and Finance, 47, 344353.

Zhang, D., Hu, M., Ji, Q., 2020. Financial markets under the global pandemic of Covid19. Finance Research Letters, 36, 101528. 
Table 1. Summary statistics

\begin{tabular}{ccccccc}
\hline Variable & Mean & S.D. & Minimum & Maximum & Skewness & Kurtosis \\
\hline XLM & 0.219 & 7.725 & -41.49 & 69.84 & 1.822 & 19.35 \\
\hline ETH & 0.341 & 6.350 & -56.56 & 30.06 & -0.253 & 10.07 \\
\hline XEM & 0.335 & 7.835 & -36.29 & 87.06 & 1.810 & 18.61 \\
\hline BTC & 0.218 & 4.113 & -47.05 & 22.40 & -0.899 & 15.86 \\
\hline XRP & 0.210 & 6.999 & -63.65 & 100.8 & 2.544 & 40.46 \\
\hline LTC & 0.161 & 5.714 & -45.87 & 55.67 & 1.194 & 17.22 \\
\hline XMR & 0.300 & 6.479 & -48.43 & 59.63 & 0.827 & 13.10 \\
\hline DASH & 0.205 & 5.944 & -47.45 & 42.56 & 0.543 & 10.81 \\
\hline BTS & 0.075 & 7.434 & -49.43 & 51.67 & 0.683 & 11.89 \\
\hline
\end{tabular}

Notes: XLM $=$ Stellar; ETH $=$ Ethereum; BTC $=$ Bitcoin; XEM $=$ Nem $/$ New Economy Movement; $\mathrm{XRP}=$ Ripple $; \mathrm{LTC}=$ Litecoin DASH $=$ Dash XMR $=$ Monero; $\mathrm{BTS}=$ Bitshare. S.D. denotes standard deviation. 
Table 2. Summary statistics of weights based on a minimum connectedness portfolio, September 2015-June 2020

\begin{tabular}{ccccccccccccc}
\hline & \multicolumn{4}{c}{ Full sample period } & \multicolumn{7}{c}{ COVID-19 period } \\
\cline { 2 - 13 } & Mean & S.D. & $\mathbf{5 \%}$ & $\mathbf{9 5 \%}$ & HE & Prob. & Mean & S.D. & $\mathbf{5 \%}$ & $\mathbf{9 5 \%}$ & HE & Prob. \\
\hline XLM & 0.1 & 0.04 & 0.03 & 0.17 & 0.72 & 0 & 0.05 & 0.06 & 0 & 0.14 & 0.49 & 0 \\
\hline ETH & 0.06 & 0.07 & 0 & 0.17 & 0.58 & 0 & 0 & 0 & 0 & 0 & 0.63 & 0 \\
\hline XEM & 0.14 & 0.03 & 0.09 & 0.18 & 0.73 & 0 & 0.22 & 0.02 & 0.17 & 0.25 & 0.46 & 0.01 \\
\hline BTC & 0.1 & 0.07 & 0 & 0.23 & 0 & 0 & 0.03 & 0.03 & 0 & 0.08 & 0.41 & 0.37 \\
\hline XRP & 0.14 & 0.05 & 0.08 & 0.24 & 0.66 & 0 & 0.14 & 0.07 & 0.04 & 0.24 & 0.36 & 0.09 \\
\hline LTC & 0.09 & 0.06 & 0 & 0.17 & 0.48 & 0 & 0 & 0 & 0 & 0.01 & 0.53 & 0.01 \\
\hline XMR & 0.07 & 0.06 & 0 & 0.15 & 0.6 & 0 & 0.08 & 0.03 & 0 & 0.12 & 0.51 & 0 \\
\hline DASH & 0.13 & 0.05 & 0.05 & 0.24 & 0.52 & 0 & 0.19 & 0.03 & 0.14 & 0.21 & 0.6 & 0 \\
\hline BTS & 0.17 & 0.08 & 0.01 & 0.26 & 0.69 & 0 & 0.29 & 0.03 & 0.27 & 0.36 & 0.69 & 0.01 \\
\hline
\end{tabular}

Notes: $\mathrm{XLM}=$ Stellar; ETH $=$ Ethereum; BTC $=$ Bitcoin; $\mathrm{XEM}=\mathrm{Nem} / \mathrm{New}$ Economy Movement; $\mathrm{XRP}=$ Ripple; $\mathrm{LTC}=$ Litecoin $; \mathrm{DASH}=$ Dash; $\mathrm{XMR}=$ Monero; BTS $=$ Bitshare. The COVID-19 Period is defined as January 2020-June 2020. 
Table 3. Summary statistics of bilateral portfolio weights, September 2015-June 2020

\begin{tabular}{|c|c|c|c|c|c|c|c|c|c|c|c|c|}
\hline \multirow[b]{2}{*}{$w_{i j}$} & \multicolumn{6}{|c|}{ Full sample period } & \multicolumn{6}{|c|}{ COVID-19 period } \\
\hline & $\begin{array}{c}\text { Mea } \\
\text { n }\end{array}$ & S.D. & $5 \%$ & $95 \%$ & HE & $\begin{array}{c}\text { p- } \\
\text { value }\end{array}$ & $\begin{array}{c}\text { Mea } \\
\text { n }\end{array}$ & S.D. & $5 \%$ & $95 \%$ & HE & $\begin{array}{c}\text { p- } \\
\text { value }\end{array}$ \\
\hline XLM/ETH & 0.38 & 0.27 & 0 & 0.89 & 0.52 & 0 & 0.84 & 0.26 & 0.21 & 1 & -0.01 & 0.94 \\
\hline XLM/XEM & 0.5 & 0.3 & 0 & 1 & 0.31 & 0 & 0.43 & 0.42 & 0 & 1 & 0.22 & 0.15 \\
\hline XLM/BTC & 0.14 & 0.17 & 0 & 0.49 & 0.72 & 0 & 0.47 & 0.35 & 0 & 0.99 & 0.06 & 0.7 \\
\hline XLM/XRP & 0.27 & 0.3 & 0 & 0.95 & 0.4 & 0 & 0.19 & 0.34 & 0 & 1 & 0.21 & 0.18 \\
\hline XLM/LTC & 0.34 & 0.25 & 0 & 0.79 & 0.49 & 0 & 0.49 & 0.39 & 0 & 1 & 0.07 & 0.66 \\
\hline XLM/XMR & 0.43 & 0.26 & 0 & 0.84 & 0.49 & 0 & 0.38 & 0.41 & 0 & 1 & 0.05 & 0.76 \\
\hline XLM/DASH & 0.36 & 0.27 & 0 & 0.91 & 0.56 & 0 & 0.53 & 0.41 & 0 & 1 & 0.05 & 0.77 \\
\hline XLM/BTS & 0.5 & 0.19 & 0.16 & 0.85 & 0.37 & 0 & 0.53 & 0.12 & 0.32 & 0.71 & 0.04 & 0.83 \\
\hline ETH/XLM & 0.62 & 0.27 & 0.11 & 1 & 0.29 & 0 & 0.16 & 0.26 & 0 & 0.79 & 0.26 & 0.08 \\
\hline ETH/XEM & 0.62 & 0.27 & 0.13 & 1 & 0.24 & 0 & 0.29 & 0.34 & 0 & 0.85 & 0.4 & 0 \\
\hline ETH/BTC & 0.15 & 0.2 & 0 & 0.55 & 0.6 & 0 & 0.29 & 0.38 & 0 & 1 & 0.31 & 0.03 \\
\hline ETH/XRP & 0.41 & 0.31 & 0 & 1 & 0.4 & 0 & 0.03 & 0.12 & 0 & 0.23 & 0.42 & 0 \\
\hline ETH/LTC & 0.47 & 0.31 & 0 & 1 & 0.37 & 0 & 0.13 & 0.3 & 0 & 1 & 0.21 & 0.16 \\
\hline ETH/XMR & 0.55 & 0.26 & 0.04 & 1 & 0.29 & 0 & 0.14 & 0.3 & 0 & 1 & 0.25 & 0.09 \\
\hline ETH/DASH & 0.44 & 0.29 & 0 & 1 & 0.34 & 0 & 0.3 & 0.36 & 0 & 1 & 0.09 & 0.59 \\
\hline ETH/BTS & 0.57 & 0.2 & 0.23 & 0.94 & 0.32 & 0 & 0.48 & 0.15 & 0.17 & 0.69 & 0.14 & 0.38 \\
\hline XEM/XLM & 0.5 & 0.3 & 0 & 1 & 0.33 & 0 & 0.57 & 0.42 & 0 & 1 & 0.17 & 0.28 \\
\hline XEM/ETH & 0.38 & 0.27 & 0 & 0.87 & 0.5 & 0 & 0.71 & 0.34 & 0.15 & 1 & 0.13 & 0.44 \\
\hline XEM/BTC & 0.13 & 0.19 & 0 & 0.53 & 0.71 & 0 & 0.53 & 0.43 & 0 & 1 & 0.1 & 0.55 \\
\hline XEM/XRP & 0.32 & 0.26 & 0 & 0.87 & 0.47 & 0 & 0.48 & 0.38 & 0 & 1 & 0.21 & 0.17 \\
\hline XEM/LTC & 0.34 & 0.27 & 0 & 0.85 & 0.52 & 0 & 0.65 & 0.4 & 0 & 1 & 0.06 & 0.72 \\
\hline XEM/XMR & 0.43 & 0.26 & 0 & 0.88 & 0.49 & 0 & 0.62 & 0.37 & 0 & 1 & 0.09 & 0.6 \\
\hline XEM/DASH & 0.35 & 0.27 & 0 & 0.92 & 0.54 & 0 & 0.68 & 0.34 & 0.06 & 1 & 0.1 & 0.52 \\
\hline XEM/BTS & 0.49 & 0.21 & 0.11 & 0.85 & 0.37 & 0 & 0.57 & 0.14 & 0.28 & 0.74 & 0.03 & 0.86 \\
\hline BTC/XLM & 0.86 & 0.17 & 0.51 & 1 & 0 & 1 & 0.53 & 0.35 & 0.01 & 1 & -0.08 & 0.66 \\
\hline BTC/ETH & 0.85 & 0.2 & 0.45 & 1 & 0.04 & 0.37 & 0.71 & 0.38 & 0 & 1 & -0.1 & 0.6 \\
\hline BTC/XEM & 0.87 & 0.19 & 0.47 & 1 & -0.06 & 0.2 & 0.47 & 0.43 & 0 & 1 & 0.02 & 0.9 \\
\hline BTC/XRP & 0.76 & 0.25 & 0.26 & 1 & 0.05 & 0.24 & 0.3 & 0.39 & 0 & 1 & 0.03 & 0.88 \\
\hline BTC/LTC & 0.85 & 0.25 & 0.24 & 1 & -0.07 & 0.15 & 0.49 & 0.41 & 0 & 1 & -0.1 & 0.59 \\
\hline BTC/XMR & 0.88 & 0.17 & 0.53 & 1 & 0.01 & 0.91 & 0.38 & 0.45 & 0 & 1 & -0.06 & 0.75 \\
\hline BTC/DASH & 0.8 & 0.22 & 0.36 & 1 & 0.07 & 0.16 & 0.52 & 0.38 & 0 & 1 & -0.06 & 0.75 \\
\hline BTC/BTS & 0.76 & 0.16 & 0.49 & 1 & 0.1 & 0.03 & 0.55 & 0.07 & 0.46 & 0.65 & 0.23 & 0.12 \\
\hline XRP/XLM & 0.73 & 0.3 & 0.05 & 1 & 0.27 & 0 & 0.81 & 0.34 & 0 & 1 & 0 & 1 \\
\hline XRP/ETH & 0.59 & 0.31 & 0 & 1 & 0.5 & 0 & 0.97 & 0.12 & 0.77 & 1 & -0.01 & 0.95 \\
\hline XRP/XEM & 0.68 & 0.26 & 0.13 & 1 & 0.34 & 0 & 0.52 & 0.38 & 0 & 1 & 0.06 & 0.71 \\
\hline XRP/BTC & 0.24 & 0.25 & 0 & 0.74 & 0.67 & 0 & 0.7 & 0.39 & 0 & 1 & -0.06 & 0.72 \\
\hline XRP/LTC & 0.53 & 0.31 & 0 & 1 & 0.46 & 0 & 0.85 & 0.31 & 0.04 & 1 & 0 & 0.98 \\
\hline $\mathrm{XRP} / \mathrm{XMR}$ & 0.63 & 0.28 & 0.05 & 1 & 0.47 & 0 & 0.81 & 0.27 & 0.12 & 1 & -0.01 & 0.93 \\
\hline XRP/DASH & 0.52 & 0.27 & 0.06 & 1 & 0.51 & 0 & 0.85 & 0.25 & 0.19 & 1 & 0 & 1 \\
\hline
\end{tabular}




\begin{tabular}{|c|c|c|c|c|c|c|c|c|c|c|c|c|}
\hline \multirow[b]{2}{*}{$w_{i j}$} & \multicolumn{6}{|c|}{ Full sample period } & \multicolumn{6}{|c|}{ COVID-19 period } \\
\hline & $\begin{array}{c}\text { Mea } \\
\text { n }\end{array}$ & S.D. & $5 \%$ & $95 \%$ & HE & $\begin{array}{c}\text { p- } \\
\text { value }\end{array}$ & $\begin{array}{c}\text { Mea } \\
\text { n }\end{array}$ & S.D. & $5 \%$ & $95 \%$ & HE & $\begin{array}{c}\text { p- } \\
\text { value }\end{array}$ \\
\hline XRP/BTS & 0.6 & 0.21 & 0.2 & 0.96 & 0.36 & 0 & 0.6 & 0.15 & 0.24 & 0.78 & -0.17 & 0.36 \\
\hline LTC/XLM & 0.66 & 0.25 & 0.21 & 1 & 0.06 & 0.17 & 0.51 & 0.39 & 0 & 1 & 0.15 & 0.35 \\
\hline LTC/ETH & 0.53 & 0.31 & 0 & 1 & 0.22 & 0 & 0.87 & 0.3 & 0 & 1 & 0.01 & 0.97 \\
\hline LTC/XEM & 0.66 & 0.27 & 0.15 & 1 & 0.1 & 0.02 & 0.35 & 0.4 & 0 & 1 & 0.19 & 0.23 \\
\hline LTC/BTC & 0.15 & 0.25 & 0 & 0.76 & 0.44 & 0 & 0.51 & 0.41 & 0 & 1 & 0.13 & 0.44 \\
\hline LTC/XRP & 0.47 & 0.31 & 0 & 1 & 0.19 & 0 & 0.15 & 0.31 & 0 & 0.96 & 0.27 & 0.06 \\
\hline LTC/XMR & 0.61 & 0.27 & 0.08 & 1 & 0.2 & 0 & 0.35 & 0.36 & 0 & 1 & 0.01 & 0.96 \\
\hline LTC/DASH & 0.49 & 0.3 & 0 & 1 & 0.23 & 0 & 0.52 & 0.36 & 0.01 & 1 & -0.04 & 0.81 \\
\hline LTC/BTS & 0.61 & 0.16 & 0.41 & 0.92 & 0.23 & 0 & 0.53 & 0.14 & 0.21 & 0.69 & -0.02 & 0.91 \\
\hline XMR/XLM & 0.57 & 0.26 & 0.16 & 1 & 0.27 & 0 & 0.62 & 0.41 & 0 & 1 & 0.09 & 0.61 \\
\hline XMR/ETH & 0.45 & 0.26 & 0 & 0.96 & 0.32 & 0 & 0.86 & 0.3 & 0 & 1 & 0.01 & 0.95 \\
\hline XMR/XEM & 0.57 & 0.26 & 0.12 & 1 & 0.25 & 0 & 0.38 & 0.37 & 0 & 1 & 0.17 & 0.27 \\
\hline XMR/BTC & 0.12 & 0.17 & 0 & 0.47 & 0.6 & 0 & 0.62 & 0.45 & 0 & 1 & 0.12 & 0.47 \\
\hline XMR/XRP & 0.37 & 0.28 & 0 & 0.95 & 0.39 & 0 & 0.19 & 0.27 & 0 & 0.88 & 0.22 & 0.14 \\
\hline XMR/LTC & 0.39 & 0.27 & 0 & 0.92 & 0.38 & 0 & 0.65 & 0.36 & 0 & 1 & -0.04 & 0.83 \\
\hline XMR/DASH & 0.38 & 0.28 & 0 & 0.98 & 0.3 & 0 & 0.66 & 0.3 & 0.16 & 1 & -0.05 & 0.79 \\
\hline $\mathrm{XMR} / \mathrm{BTS}$ & 0.54 & 0.19 & 0.24 & 0.9 & 0.34 & 0 & 0.56 & 0.16 & 0.2 & 0.77 & -0.04 & 0.84 \\
\hline DASH/XLM & 0.64 & 0.27 & 0.09 & 1 & 0.26 & 0 & 0.47 & 0.41 & 0 & 1 & 0.25 & 0.1 \\
\hline DASH/ETH & 0.56 & 0.29 & 0 & 1 & 0.25 & 0 & 0.7 & 0.36 & 0 & 1 & 0.01 & 0.96 \\
\hline DASH/XEM & 0.65 & 0.27 & 0.08 & 1 & 0.2 & 0 & 0.32 & 0.34 & 0 & 0.94 & 0.33 & 0.02 \\
\hline $\mathrm{DASH} / \mathrm{BTC}$ & 0.2 & 0.22 & 0 & 0.64 & 0.55 & 0 & 0.48 & 0.38 & 0 & 1 & 0.27 & 0.06 \\
\hline DASH/XRP & 0.48 & 0.27 & 0 & 0.94 & 0.32 & 0 & 0.15 & 0.25 & 0 & 0.81 & 0.37 & 0.01 \\
\hline $\mathrm{DASH} / \mathrm{LTC}$ & 0.51 & 0.3 & 0 & 1 & 0.28 & 0 & 0.48 & 0.36 & 0 & 0.99 & 0.1 & 0.52 \\
\hline DASH/XMR & 0.62 & 0.28 & 0.02 & 1 & 0.17 & 0 & 0.34 & 0.3 & 0 & 0.84 & 0.14 & 0.38 \\
\hline DASH/BTS & 0.59 & 0.18 & 0.25 & 0.91 & 0.32 & 0 & 0.53 & 0.16 & 0.15 & 0.7 & 0.13 & 0.42 \\
\hline BTS/XLM & 0.5 & 0.19 & 0.15 & 0.84 & 0.32 & 0 & 0.47 & 0.12 & 0.29 & 0.68 & 0.41 & 0 \\
\hline BTS/ETH & 0.43 & 0.2 & 0.06 & 0.77 & 0.5 & 0 & 0.52 & 0.15 & 0.31 & 0.83 & 0.28 & 0.06 \\
\hline BTS/XEM & 0.51 & 0.21 & 0.15 & 0.89 & 0.29 & 0 & 0.43 & 0.14 & 0.26 & 0.72 & 0.44 & 0 \\
\hline BTS/BTC & 0.24 & 0.16 & 0 & 0.51 & 0.72 & 0 & 0.45 & 0.07 & 0.35 & 0.54 & 0.59 & 0 \\
\hline BTS/XRP & 0.4 & 0.21 & 0.04 & 0.8 & 0.43 & 0 & 0.4 & 0.15 & 0.22 & 0.76 & 0.43 & 0 \\
\hline BTS/LTC & 0.39 & 0.16 & 0.08 & 0.59 & 0.55 & 0 & 0.47 & 0.14 & 0.31 & 0.79 & 0.32 & 0.03 \\
\hline BTS/XMR & 0.46 & 0.19 & 0.1 & 0.76 & 0.5 & 0 & 0.44 & 0.16 & 0.23 & 0.8 & 0.34 & 0.02 \\
\hline BTS/DASH & 0.41 & 0.18 & 0.09 & 0.75 & 0.56 & 0 & 0.47 & 0.16 & 0.3 & 0.85 & 0.33 & 0.02 \\
\hline
\end{tabular}

Note: $\mathrm{XLM}=$ Stellar; ETH $=$ Ethereum; BTC = Bitcoin; XEM = Nem $/$ New Economy Movement; $\mathrm{XRP}=$ Ripple; $\mathrm{LTC}=$ Litecoin; $\mathrm{DASH}=$ Dash $; \mathrm{XMR}=$ Monero; BTS $=$ Bitshares. The COVID-19

Period is defined as January 2020-June 2020. 
Table 4. Summary statistics of bilateral hedge ratios, September 2015-June 2020

\begin{tabular}{|c|c|c|c|c|c|c|c|c|c|c|c|c|}
\hline \multirow[b]{2}{*}{$w_{i j}$} & \multicolumn{6}{|c|}{ Full sample period } & \multicolumn{6}{|c|}{ COVID-19 period* } \\
\hline & $\begin{array}{c}\text { Mea } \\
\text { n }\end{array}$ & S.D. & $5 \%$ & $\begin{array}{l}95 \\
\%\end{array}$ & HE & $\begin{array}{c}\text { p- } \\
\text { value }\end{array}$ & $\begin{array}{c}\text { Mea } \\
\text { n }\end{array}$ & S.D. & $5 \%$ & $95 \%$ & HE & $\begin{array}{c}\text { p- } \\
\text { value }\end{array}$ \\
\hline ETH/XLM & 0.45 & 0.29 & -0.03 & 0.9 & 0.17 & 0 & 1.05 & 0.17 & 0.82 & 1.38 & 0.8 & 0 \\
\hline XEM/XLM & 0.57 & 0.27 & 0.17 & 1.01 & 0.23 & 0 & 0.73 & 0.21 & 0.45 & 1.06 & 0.65 & 0 \\
\hline BTC/XLM & 0.32 & 0.2 & 0.03 & 0.61 & 0.15 & 0 & 0.83 & 0.13 & 0.6 & 1 & 0.7 & 0 \\
\hline XRP/XLM & 0.59 & 0.24 & 0.22 & 0.95 & 0.32 & 0 & 0.8 & 0.15 & 0.63 & 1.13 & 0.82 & 0 \\
\hline LTC/XLM & 0.47 & 0.27 & 0.08 & 0.87 & 0.17 & 0 & 0.91 & 0.16 & 0.69 & 1.21 & 0.79 & 0 \\
\hline XMR/XLM & 0.49 & 0.25 & 0.07 & 0.87 & 0.25 & 0 & 0.86 & 0.18 & 0.62 & 1.23 & 0.75 & 0 \\
\hline $\begin{array}{c}\mathrm{DASH} / \mathrm{XL} \\
\mathrm{M}\end{array}$ & 0.43 & 0.28 & 0.04 & 0.87 & 0.16 & 0 & 0.9 & 0.22 & 0.64 & 1.45 & 0.65 & 0 \\
\hline BTS/XLM & 0.22 & 0.24 & -0.04 & 0.72 & 0.02 & 0.69 & -0.02 & 0.02 & -0.05 & 0.01 & -0.12 & 0.5 \\
\hline XLM/ETH & 0.61 & 0.4 & -0.01 & 1.12 & 0.26 & 0 & 0.8 & 0.09 & 0.63 & 0.95 & 0.81 & 0 \\
\hline XEM/ETH & 0.6 & 0.38 & 0.02 & 1.1 & 0.26 & 0 & 0.66 & 0.19 & 0.41 & 0.91 & 0.71 & 0 \\
\hline BTC/ETH & 0.41 & 0.26 & -0.03 & 0.8 & 0.34 & 0 & 0.79 & 0.18 & 0.44 & 1.02 & 0.67 & 0 \\
\hline XRP/ETH & 0.55 & 0.34 & 0.04 & 1.03 & 0.31 & 0 & 0.71 & 0.09 & 0.55 & 0.89 & 0.87 & 0 \\
\hline LTC/ETH & 0.58 & 0.36 & 0 & 1.05 & 0.3 & 0 & 0.84 & 0.1 & 0.68 & 1.04 & 0.89 & 0 \\
\hline XMR/ETH & 0.62 & 0.28 & 0.15 & 1.01 & 0.32 & 0 & 0.78 & 0.12 & 0.6 & 1.01 & 0.85 & 0 \\
\hline DASH/ETH & 0.58 & 0.33 & 0.08 & 1.04 & 0.29 & 0 & 0.81 & 0.14 & 0.61 & 1.07 & 0.69 & 0 \\
\hline BTS/ETH & 0.23 & 0.26 & -0.01 & 0.82 & 0.02 & 0.68 & 0.03 & 0.02 & 0.01 & 0.05 & -0.33 & 0.1 \\
\hline XLM/XEM & 0.57 & 0.34 & 0.11 & 1.05 & 0.25 & 0 & 0.89 & 0.28 & 0.49 & 1.33 & 0.63 & 0 \\
\hline ETH/XEM & 0.45 & 0.28 & 0.03 & 0.91 & 0.12 & 0.01 & 1.05 & 0.34 & 0.59 & 1.59 & 0.64 & 0 \\
\hline BTC/XEM & 0.31 & 0.21 & 0.04 & 0.67 & 0.21 & 0 & 0.84 & 0.28 & 0.51 & 1.27 & 0.6 & 0 \\
\hline XRP/XEM & 0.43 & 0.27 & 0.06 & 0.87 & 0.08 & 0.09 & 0.78 & 0.2 & 0.45 & 1.08 & 0.6 & 0 \\
\hline LTC/XEM & 0.43 & 0.28 & 0.05 & 0.88 & -0.02 & 0.72 & 0.95 & 0.24 & 0.52 & 1.32 & 0.7 & 0 \\
\hline XMR/XEM & 0.45 & 0.26 & 0.05 & 0.87 & 0.16 & 0 & 0.84 & 0.22 & 0.46 & 1.19 & 0.63 & 0 \\
\hline $\begin{array}{c}\text { DASH/XE } \\
\mathrm{M} \\
\end{array}$ & 0.43 & 0.28 & 0.04 & 0.9 & 0.16 & 0 & 0.9 & 0.24 & 0.56 & 1.26 & 0.56 & 0 \\
\hline BTS/XEM & 0.17 & 0.23 & -0.05 & 0.67 & -0.01 & 0.84 & -0.04 & 0.02 & -0.08 & -0.01 & -0.06 & 0.74 \\
\hline $\mathrm{XLM} / \mathrm{BTC}$ & 0.83 & 0.44 & 0.12 & 1.54 & 0.34 & 0 & 0.91 & 0.23 & 0.73 & 1.33 & 0.7 & 0 \\
\hline ETH/BTC & 0.81 & 0.5 & -0.13 & 1.51 & 0.46 & 0 & 1.14 & 0.44 & 0.81 & 2.02 & 0.78 & 0 \\
\hline XEM/BTC & 0.89 & 0.44 & 0.2 & 1.64 & 0.33 & 0 & 0.76 & 0.27 & 0.43 & 1.33 & 0.59 & 0 \\
\hline XRP/BTC & 0.71 & 0.43 & 0.08 & 1.33 & 0.34 & 0 & 0.82 & 0.31 & 0.56 & 1.59 & 0.7 & 0 \\
\hline LTC/BTC & 1.03 & 0.31 & 0.53 & 1.55 & 0.45 & 0 & 0.97 & 0.36 & 0.68 & 1.75 & 0.75 & 0 \\
\hline XMR/BTC & 0.94 & 0.43 & 0.21 & 1.49 & 0.45 & 0 & 0.97 & 0.38 & 0.66 & 1.8 & 0.78 & 0 \\
\hline DASH/BTC & 0.78 & 0.44 & 0.09 & 1.45 & 0.39 & 0 & 0.95 & 0.41 & 0.59 & 2 & 0.63 & 0 \\
\hline BTS/BTC & 0.28 & 0.35 & -0.08 & 1.04 & 0.01 & 0.91 & -0.03 & 0.02 & -0.06 & 0 & -0.05 & 0.79 \\
\hline XLM/XRP & 0.86 & 0.33 & 0.38 & 1.34 & 0.44 & 0 & 1.06 & 0.16 & 0.78 & 1.3 & 0.87 & 0 \\
\hline ETH/XRP & 0.6 & 0.34 & 0.06 & 1.11 & 0.2 & 0 & 1.23 & 0.18 & 0.95 & 1.56 & 0.87 & 0 \\
\hline XEM/XRP & 0.64 & 0.34 & 0.13 & 1.11 & 0.21 & 0 & 0.84 & 0.18 & 0.63 & 1.15 & 0.7 & 0 \\
\hline BTC/XRP & 0.39 & 0.25 & 0.02 & 0.81 & 0.17 & 0 & 0.97 & 0.23 & 0.52 & 1.3 & 0.69 & 0 \\
\hline LTC/XRP & 0.57 & 0.35 & 0.08 & 1.11 & 0.14 & 0 & 1.07 & 0.14 & 0.84 & 1.26 & 0.86 & 0 \\
\hline XMR/XRP & 0.58 & 0.32 & 0.09 & 1.06 & 0.19 & 0 & 0.97 & 0.11 & 0.73 & 1.14 & 0.8 & 0 \\
\hline
\end{tabular}




\begin{tabular}{|c|c|c|c|c|c|c|c|c|c|c|c|c|}
\hline \multirow[b]{2}{*}{$w_{i j}$} & \multicolumn{6}{|c|}{ Full sample period } & \multicolumn{6}{|c|}{ COVID-19 period* } \\
\hline & $\begin{array}{c}\text { Mea } \\
\text { n }\end{array}$ & S.D. & $5 \%$ & $\begin{array}{l}95 \\
\% \\
\end{array}$ & HE & $\begin{array}{c}\text { p- } \\
\text { value }\end{array}$ & $\begin{array}{c}\text { Mea } \\
\text { n }\end{array}$ & S.D. & $5 \%$ & $95 \%$ & HE & $\begin{array}{c}\text { p- } \\
\text { value }\end{array}$ \\
\hline DASH/XRP & 0.5 & 0.33 & 0.05 & 1.08 & 0.16 & 0 & 1.01 & 0.15 & 0.7 & 1.24 & 0.63 & 0 \\
\hline BTS/XRP & 0.24 & 0.27 & -0.06 & 0.83 & 0.11 & 0.02 & 0.01 & 0.03 & -0.02 & 0.06 & -0.17 & 0.37 \\
\hline $\mathrm{XLM} / \mathrm{LTC}$ & 0.65 & 0.31 & 0.14 & 1.16 & 0.31 & 0 & 0.89 & 0.13 & 0.7 & 1.1 & 0.82 & 0 \\
\hline ETH/LTC & 0.6 & 0.36 & -0.01 & 1.11 & 0.45 & 0 & 1.07 & 0.13 & 0.82 & 1.28 & 0.89 & 0 \\
\hline $\mathrm{XEM} / \mathrm{LTC}$ & 0.64 & 0.35 & 0.09 & 1.22 & 0.29 & 0 & 0.77 & 0.18 & 0.55 & 1.12 & 0.74 & 0 \\
\hline $\mathrm{BTC} / \mathrm{LTC}$ & 0.55 & 0.18 & 0.24 & 0.86 & 0.45 & 0 & 0.86 & 0.19 & 0.48 & 1.12 & 0.74 & 0 \\
\hline $\mathrm{XRP} / \mathrm{LTC}$ & 0.57 & 0.32 & 0.08 & 1.09 & 0.32 & 0 & 0.8 & 0.1 & 0.66 & 0.99 & 0.86 & 0 \\
\hline XMR/LTC & 0.63 & 0.28 & 0.09 & 1.02 & 0.36 & 0 & 0.88 & 0.12 & 0.68 & 1.09 & 0.84 & 0 \\
\hline DASH/LTC & 0.56 & 0.32 & 0.06 & 1.09 & 0.34 & 0 & 0.9 & 0.13 & 0.72 & 1.16 & 0.69 & 0 \\
\hline BTS/LTC & 0.17 & 0.24 & -0.07 & 0.7 & 0.02 & 0.68 & 0.01 & 0.02 & -0.01 & 0.04 & -0.25 & 0.19 \\
\hline XLM/XMR & 0.59 & 0.35 & 0.11 & 1.08 & 0.27 & 0 & 0.94 & 0.16 & 0.7 & 1.19 & 0.78 & 0 \\
\hline ETH/XMR & 0.57 & 0.26 & 0.13 & 0.96 & 0.3 & 0 & 1.11 & 0.16 & 0.85 & 1.4 & 0.85 & 0 \\
\hline XEM/XMR & 0.54 & 0.31 & 0.08 & 1.01 & 0.21 & 0 & 0.75 & 0.19 & 0.53 & 1.11 & 0.65 & 0 \\
\hline BTC/XMR & 0.4 & 0.21 & 0.05 & 0.74 & 0.32 & 0 & 0.95 & 0.23 & 0.5 & 1.27 & 0.67 & 0 \\
\hline XRP/XMR & 0.47 & 0.3 & 0.07 & 0.91 & 0.25 & 0 & 0.8 & 0.08 & 0.69 & 0.95 & 0.8 & 0 \\
\hline LTC/XMR & 0.52 & 0.28 & 0.07 & 0.94 & 0.27 & 0 & 0.97 & 0.12 & 0.78 & 1.2 & 0.84 & 0 \\
\hline $\begin{array}{c}\mathrm{DASH} / \mathrm{XM} \\
\mathrm{R}\end{array}$ & 0.56 & 0.28 & 0.11 & 0.99 & 0.31 & 0 & 0.92 & 0.14 & 0.74 & 1.17 & 0.64 & 0 \\
\hline BTS/XMR & 0.18 & 0.24 & -0.06 & 0.73 & 0.03 & 0.54 & 0.03 & 0.02 & 0 & 0.07 & -0.22 & 0.25 \\
\hline $\begin{array}{c}\text { XLM/DAS } \\
\mathrm{H} \\
\end{array}$ & 0.58 & 0.37 & 0.08 & 1.12 & 0.23 & 0 & 0.84 & 0.16 & 0.53 & 1.08 & 0.62 & 0 \\
\hline ETH/DASH & 0.61 & 0.3 & 0.13 & 1.02 & 0.34 & 0 & 0.99 & 0.17 & 0.75 & 1.3 & 0.71 & 0 \\
\hline $\begin{array}{c}\text { XEM/DAS } \\
\mathrm{H} \\
\end{array}$ & 0.61 & 0.32 & 0.14 & 1.14 & 0.24 & 0 & 0.7 & 0.17 & 0.48 & 0.95 & 0.58 & 0 \\
\hline BTC/DASH & 0.4 & 0.24 & 0.04 & 0.77 & 0.34 & 0 & 0.8 & 0.21 & 0.4 & 1.13 & 0.51 & 0 \\
\hline XRP/DASH & 0.47 & 0.32 & 0.08 & 0.92 & 0.24 & 0 & 0.72 & 0.1 & 0.56 & 0.91 & 0.65 & 0 \\
\hline LTC/DASH & 0.55 & 0.32 & 0.07 & 1 & 0.3 & 0 & 0.86 & 0.11 & 0.68 & 1 & 0.69 & 0 \\
\hline $\begin{array}{c}\text { XMR/DAS } \\
\mathrm{H} \\
\end{array}$ & 0.65 & 0.26 & 0.22 & 1.01 & 0.35 & 0 & 0.8 & 0.12 & 0.62 & 0.94 & 0.66 & 0 \\
\hline BTS/DASH & 0.16 & 0.23 & -0.09 & 0.71 & 0 & 0.92 & 0.02 & 0.02 & -0.01 & 0.05 & -0.18 & 0.33 \\
\hline XLM/BTS & 0.23 & 0.28 & -0.04 & 0.69 & 0.12 & 0.01 & -0.02 & 0.03 & -0.06 & 0.01 & -0.01 & 0.96 \\
\hline ETH/BTS & 0.16 & 0.15 & -0.01 & 0.43 & 0.11 & 0.02 & 0.03 & 0.06 & 0.01 & 0.08 & 0 & 0.99 \\
\hline XEM/BTS & 0.17 & 0.22 & -0.06 & 0.53 & 0.07 & 0.13 & -0.03 & 0.03 & -0.07 & 0 & -0.01 & 0.98 \\
\hline BTC/BTS & 0.08 & 0.1 & -0.03 & 0.27 & 0.07 & 0.13 & -0.02 & 0.02 & -0.05 & 0 & -0.01 & 0.96 \\
\hline XRP/BTS & 0.15 & 0.19 & -0.06 & 0.5 & 0.07 & 0.16 & 0 & 0.03 & -0.02 & 0.03 & -0.01 & 0.97 \\
\hline LTC/BTS & 0.09 & 0.13 & -0.07 & 0.31 & 0.03 & 0.52 & 0.01 & 0.04 & -0.02 & 0.05 & -0.01 & 0.98 \\
\hline XMR/BTS & 0.13 & 0.15 & -0.06 & 0.37 & 0.07 & 0.11 & 0.03 & 0.05 & 0 & 0.07 & 0 & 1 \\
\hline DASH/BTS & 0.1 & 0.13 & -0.07 & 0.33 & 0.04 & 0.4 & 0.02 & 0.04 & -0.01 & 0.06 & 0 & 0.98 \\
\hline
\end{tabular}

Notes: $\mathrm{XLM}=$ Stellar; ETH $=$ Ethereum; BTC $=$ Bitcoin; $\mathrm{XEM}=\mathrm{Nem} / \mathrm{New}$ Economy Movement; $\mathrm{XRP}=$ Ripple; $\mathrm{LTC}=$ Litecoin; DASH $=$ Dash; XMR = Monero; BTS = Bitshares. ${ }^{*}$ The COVID-19 Period is defined as January 2020-June 2020. 
Figure 1. Dynamic conditional correlations (DCC) based on a minimum connectedness portfolio

(a) Full sample period

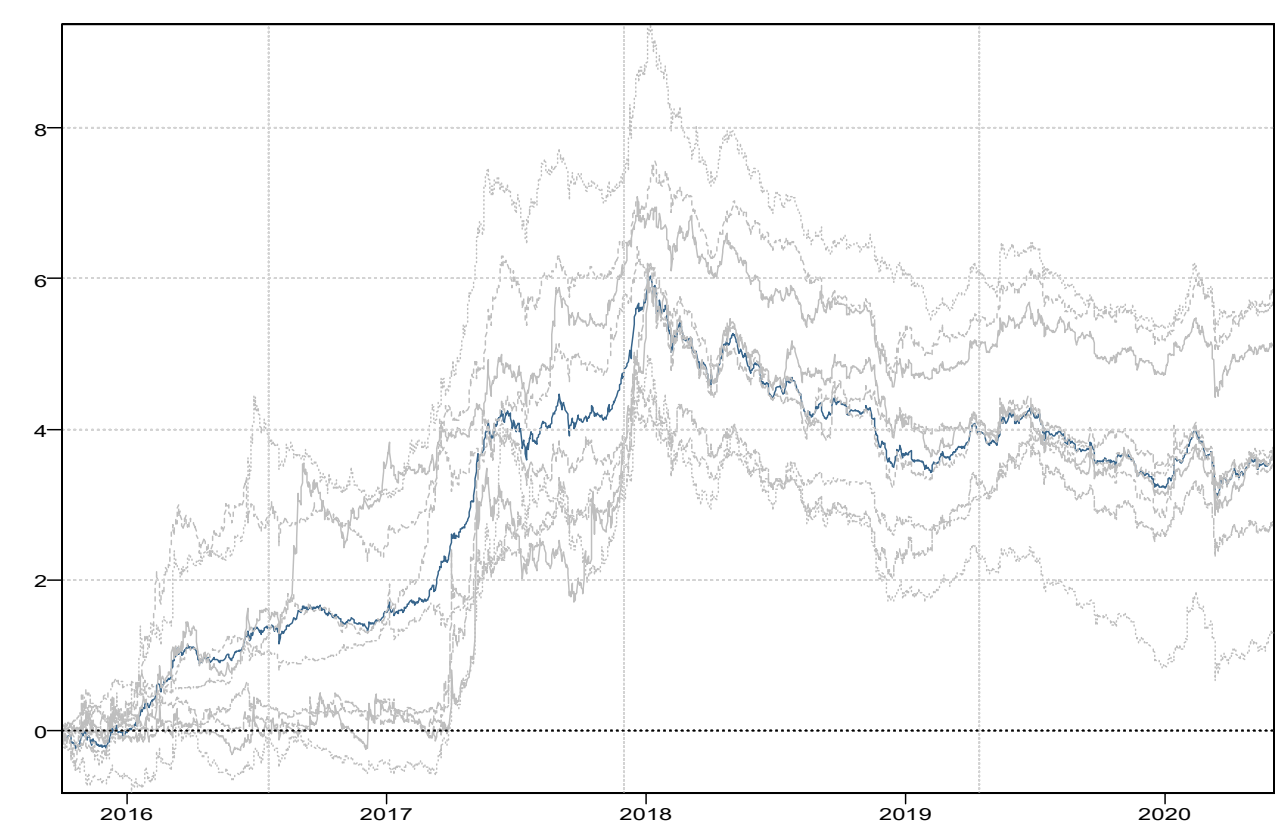

(b) During the COVID-19 period

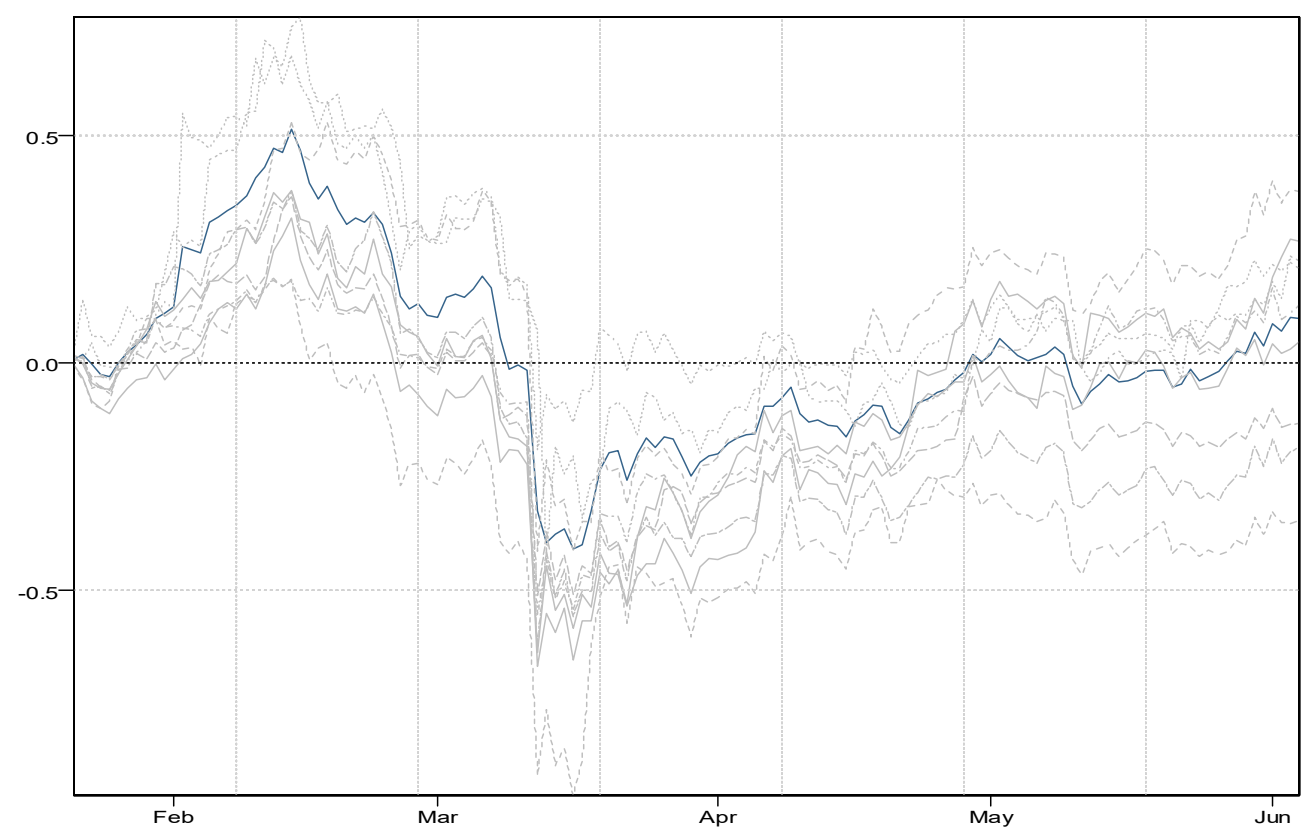

